\title{
Integrated Supply Chain for a Single Vendor and Multiple Buyers and Products with Crashing Lead Time
}

\author{
Kinley Aritonang ${ }^{1 *}$, Marihot Nainggolan ${ }^{1}$, Adrianus Vincent Djunaidi ${ }^{1}$ \\ ${ }^{1}$ Department of Industrial Engineering Faculty of Industrial Technology Universitas Katolik Parahyangan, \\ Jalan Ciumbuleuit 94 Bandung 40141, Indonesia
}

\begin{abstract}
In this study, an integrated inventory model was developed among one vendor, multi buyers, and multi products. The total inventory cost to be minimized in this model is a combination of the vendor's and the buyers' total inventory costs. The total vendor inventory costs consist of setup costs and holding costs and the total inventory cost of the buyer consists of ordering costs, holding costs, stockout costs, and crashing lead time costs where the crashing lead time cost is approximated with an exponential function. Three decision variables will be calculated: the number of buyer orders, the lead time of each buyer, and the frequency of vendor shipments to all buyers in one production cycle. In this study, the optimal solution of each decision variable has been developed and applied to a case to show the use of models for finding optimal solutions. The sensitivity has also been performed to show the effects of some factors on the decision variables.
\end{abstract}

Keywords: Crashing lead time; Integrated inventory model; Inventory management; Multi products; Multi buyers

\section{Introduction}

There are many ways that companies maintain customer trust; one of them is trying to consistently fulfil the customer's demand. This goal utilizes a supply chain in many fields, such as the Malaysian automotive industry (Ashari et al., 2018), school feeding program in the Philippines (Miro et al., 2018), Malaysian public sector projects (Riazi and Nawi, 2018), etc. Supply chains rely much on inventory management. According to Tersine (1994), important component in inventory management is lead, which usually consists of several components: order preparation, supplier lead time, delivery time, and setup time. In real world conditions, one or more the lead time components can usually be reduced by incurring the additional costs, usually known as the crashing lead time costs (Jha and Shanker, 2009). With the option to reduce it, lead time can also be one of the decision variables in inventory management where a company wants to have a shorter lead time. Therefore, if the company has the option to reduce its lead times, it can minimize the total cost of inventory. Liao and Shyu (1991) consider the possibility of crashing lead time and developed an inventory model that makes the lead time as a decision variable by assuming the number of products ordered is known and the demand follows normal distribution.

The lead time is assumed to consist of $\mathrm{n}$ components which each component has the crashing lead time costs. Liao and Shyu's model has been continued by Ben-Daya and Raouf (1994).

*Corresponding author's email: kinley@unpar.ac.id, Tel.: +62-81322578757 
Their inventory model made the lead time and number of products ordered decision variables. Ouyang et al. (1996) then developed an inventory model that could reduce the lead times, and considered the occurrence of a stockout with backorder and lost sales at the same time (partial backorder). They also assumed that lead time consists of $n$ independent components. Moon and Choi (1998) developed a crashing lead time inventory model that considered the stockout (partial backorder). They determined that the number of ordered products, lead time, and reorder points were the decision variables. Chang and Chang (2001) developed a crashing lead time inventory model by considering the quantity discount and later developed a crashing lead time inventory model that considered the resources limitations and the seasonal demand (Chen and Chang 2007).

In the supply chain, the increased competition and customer demands make a company continue to improve the efficiency of its operational activities to reduce the costs. This requires a good coordination or integration in its supply chain. In an integrated inventory model, the total cost to be minimized is the combined total cost of several parties involved. Pan and Yang (2002) developed an integrated inventory model between one vendor and one buyer that considered the crashing lead time. Ouyang et al. (2004) developed Pan and Yang's research by considering the stockout (fully backorder). Yang and Pan (2004) again developed an integrated inventory model between one vendor and one buyer that considered crashing lead time and the investment cost for quality improvement.

Jha and Shanker (2009) developed an inventory model that integrates one vendor and one buyer. In the model, there is one additional decision variable that must be determined: the number or frequency of delivery from vendor to buyer in one production cycle. They assumed that the vendor uses a batch production system, while the buyer uses a continuous review policy or inventory system of method Q. Jha and Shanker (2013) further developed an inventory model that integrates one vendor and several buyers, considering the possibility of reducing lead times accompanied by the service level limits. However, this model has never been developed into a multi-product inventory model. Zhu and Xu (2012) developed the optimized design of a closed-loop supply chain on an uncertain environment where dynamic state of location, facility extension, and capacity improvement were considered. Vijayashree and Uthayakumar (2016) also developed a model of inventory with the possibility to reduce the lead time. The model did not consider the stockout costs and assumed that the cost of crashing lead time is approximated by an exponential function with the maximum value of LE and can be reduced to a minimum value of LS. By reducing the lead time, a company can reduce the amount of safety stock, reduce the possibility of stockouts, and increase the service levels. Then, they improved the model by considering three lead time crashing cost functions (2017). An integrated inventory model finds the optimal solutions of order quantity, lead time, total cost for the buyer, total cost for the vendor, and the total number of deliveries. These two papers present an integrated single vendor and single buyer inventory model to minimize the sum of the cost of ordering, setup, holding, and crashing by simultaneously optimizing the optimal order quantity, lead time, and number of deliveries. The main contribution of these two proposed models is to find and minimize the integrated total cost for the single vendor and single buyer. The study of a single vendor-buyer model with stochastic demand and transportation cost was also investigated by Ivan and Hui (2018). In this study, the transportation cost was a function of shipping weight, distance, and transportation modes. A heuristic model was developed to minimize the integrated total relevant cost, and the decision variables were the buyer's order quantity and the vendor's production quantity per cycle. They then considered defective items and error in inspection (2019). The results showed that lead-time can be shortened with smaller production lot sizes. Mofokeng and Chinomona (2019) found that partnership, collaboration, and integration can generally influence the performance of supply chain, particularly within the small and medium enterprise (SME). The research explained some general factors that affect the supply chain performance. 
No single study takes into full consideration the factors of one vendor, multi buyers, multi products, crashing lead-time, and stockout. In this study, the continuation of an integrated inventory model has been carried out by considering all these factors. The total inventory cost, as the supply chain performance and to be minimized in this model, is a combination of the vendor's and the buyer's total inventory costs.

\section{Methods}

This study derived a supply chain integrated model or the inventory integrated model that consists of one vendor, multi buyers, and multi products represented by the total inventory cost of joint vendor inventory and all buyers for multi items, as shown in Equation 1 . The total vendor inventory costs consists of setup costs and holding costs. The total buyer inventory cost consists of ordering costs, holding costs, stock out costs, and crashing lead time costs. The existence of stockouts (partial backorder) and the possibility for buyers to reduce leads time was considered in the model. The model was used to determine the number of buyer orders (the order size) for each product, the lead time for each product, and the frequency of shipments from the vendor to buyers in one production cycle. The model was used for a case using a hypothetical data. The sensitivity analysis was also performed to show the effect of some parameters to the decision variables.

The following are the notations used in this study;

$W \quad$ : Index for the number of products.

$G_{i} \quad$ : Vendor setup cost for item $i$.

$m_{i} \quad$ : The frequency of vendor shipments to all buyers in one production cycle for item $i$.

$F_{i} \quad:$ The number of item $i$ ordered by all buyers.

$h v_{i} \quad$ :The vendor holding costs per unit per year for item $i$.

$P_{i} \quad$ : The vendor production rate for item $i$.

$N \quad$ : Index for the number of buyers.

$B_{i} \quad:$ The total demand per year for all buyers for item $i$.

$A_{i j} \quad$ : The ordering cost for buyer $j$ and for item $i$.

$D_{i j} \quad$ : The demand per year for buyer $j$ and for item $i$.

$Q_{i j} \quad:$ The number of item $i$ ordered by buyer $j$.

$h_{i j} \quad$ : The holding cost for buyer $j$ and for item $i$.

$k_{i j} \quad:$ The safety factor for buyer $j$ and for item $i$ where: $\mathrm{P}\left(\mathrm{Z}>k_{i j}\right)=q_{i j}$

$q_{i j} \quad$ : The percentage of allowable stock out for buyer $j$ and for item $i$.

$\sigma_{i j} \quad$ : The standard deviation of demand for buyer $j$ and for item $i$.

$L_{i j} \quad$ : The lead time for buyer $j$ and for item $i$.

$\beta_{i j} \quad$ : The backorder fraction demand for buyer $j$ and for item $i$.

$\Phi \quad$ : The cumulative distribution function of a standard normal distribution.

$\phi \quad$ : The density function of a standard normal distribution.

$\pi_{i j} \quad:$ The backorder cost for buyer $j$ and for item $i$.

$\pi_{0 i j} \quad$ : The lost sales cost for buyer $j$ and for item $i$.

$R\left(L_{i j}\right)$ : The crashing lead time costs function when a buyer $j$ places an order for item $i$.

$c_{i j} \quad$ : The positive constant on exponential function of crashing lead time for buyer $j$ and item $i$.

\subsection{Model Formulation and Assumptions}

The study used the following assumptions:

1. The system consists of multi buyers supplied with multi products by one vendor.

2. Every item has a production process that is independent from one another.

3. The buyer $j$ orders the $Q_{i j}$ unit of item $i$ to the vendor. The vendor manufactures $m_{i} F_{i}$ for item $i$ with the production rate of $P_{i}$, then $Q_{i j}=F_{i} \frac{D_{i j}}{B_{i}}$

4. The vendor's production rate $P_{i}$ is greater than the customer's demand for each item. 
5. Buyers use the continuous review inventory policy.

6. The demands for each buyer are probabilistic and are assumed to follow a normal distribution.

7. Backorder stock-out fractions are known.

8. The crashing lead time cost is assumed to increase exponentially as the amount of lead time reduced and this cost will be charged to the buyer.

In this study, the mathematical models derived by Jha and Shanker (2013) will be developed by the case of multi products. Based on Figure 1, a vendor will supply several types of products to several buyers and it can be stated, therefore $B_{i}=\sum_{j=1}^{N} D_{i j}$.

Each buyer $j$ will order the item $i$ with order size $Q_{i j}$, and then the vendor will start the production with a constant rate of $P_{i}$. The vendor will produce $m_{i} F_{i}$ unit item $i$ in one production cycle $m_{i} \frac{F_{i}}{B_{i}}$, where $F_{i}=\sum_{j=1}^{N} Q_{i j}$. In one production cycle, the vendor will send $F_{i}$ units of the item $i$ for $m_{i}$ times to fulfill the demand for the item $i$ and each buyer $J$ will receive the size of the $Q_{i j}$ units. The number of item $i$ ordered by each buyer $j$ will be in accordance with the proportion of the demand for each buyer for the item, that is $Q_{i j}=F_{i} \frac{D_{i j}}{B_{i}}$ (as stated in the assumption).

The vendor will start to send the $F_{i}$ units of the item $i$ after the period of $\frac{F_{i}}{P_{i}}$; they will then continue shipping the products to all buyers at the time of $\frac{F_{i}}{B_{i}}$ until the inventory of products runs out. The total inventory cost model is a combination of the total vendor inventory costs for all products plus the total cost of inventory of all buyers for all products. The total vendor inventory costs consist of the setup costs and holding costs. Both of these cost components will be developed based on the research conducted by Jha and Shanker (2013). The buyers' total inventory cost consists of the ordering cost, the holding cost, the stockout costs, and the cost of crashing lead time for all buyers. The ordering cost of all buyers was also developed based on the research conducted by Jha and Shanker (2013). The holding and stockout costs of all buyers are developed based on the research conducted by Ouyang et al. (1996) and the crashing lead time cost will be developed based on the research conducted by Vijayashree and Uthayakumar (2016). Equation 1 shows the total inventory cost of joint vendor inventory and all buyers for item $i$

$T C G\left(Q_{i j}, L_{i j}, m_{i}\right)=$ The vendor setup costs + the vendor holding costs + the buyer ordering costs + the buyer holding cost + the buyer stockout cost + the crashing lead time costs

$$
\begin{aligned}
= & G_{i} \\
& \frac{B_{i}}{m_{i} F_{i}}+h v_{i} \frac{F_{i}}{2}\left[m_{i}\left(1-\frac{B_{i}}{P_{i}}\right)-1+\frac{2 B_{i}}{P_{i}}\right]+\sum_{j=1}^{N} A_{i j} \frac{D_{i j}}{Q_{i j}}+ \\
& \sum_{j=1}^{N} h_{i j}\left[\frac{Q_{i j}}{2}+k_{i j} \sigma_{i j} \sqrt{L_{i j}}+\left(1-\beta_{i j}\right)\left(\sigma_{i j} \sqrt{L_{i j}} \Psi\left(k_{i j}\right)\right)\right]+ \\
& \sum_{j=1}^{N} \frac{D_{i j}}{Q_{i j}}\left[\pi_{i j}+\pi_{o i j}\left(1-\beta_{i j}\right)\right]\left(\sigma_{i j} \sqrt{L_{i j}} \Psi\left(k_{i j}\right)\right)+ \\
& \sum_{j=1}^{N} \frac{D_{i j}}{Q_{i j}} R\left(L_{i j}\right)
\end{aligned}
$$

By doing a modification in Equation 1, the following equation is obtained;

$$
\begin{gathered}
\operatorname{TCG}\left(F_{i}, L_{i j}, m_{i}\right)=\sum_{i=1}^{W} G_{i} \frac{B_{i}}{m_{i} F_{i}}+\sum_{i=1}^{W} h v_{i} \frac{F_{i}}{2}\left[m_{i}\left(1-\frac{B_{i}}{P_{i}}\right)-1+\frac{2 B_{i}}{P_{i}}\right]+\sum_{i=1}^{W} \sum_{j=1}^{N} A_{i j} \frac{B_{i}}{F_{i}}+ \\
\sum_{i=1}^{W} \sum_{j=1}^{N} h_{i j}\left[\frac{F_{i}}{2 B_{i}} D_{i j}+k_{i j} \sigma_{i j} \sqrt{L_{i j}}+\left(1-\beta_{i j}\right)\left(\sigma_{i j} \sqrt{L_{i j}} \Psi\left(k_{i j}\right)\right)\right]+
\end{gathered}
$$




$$
\sum_{i=1}^{W} \sum_{j=1}^{N} \frac{B_{i}}{F_{i}}\left[\pi_{i j}+\pi_{o i j}\left(1-\beta_{i j}\right)\right]\left(\sigma_{i j} \sqrt{L_{i j}} \Psi\left(k_{i j}\right)\right)+\sum_{i=1}^{W} \sum_{j=1}^{N} \frac{B_{i}}{F_{i}} R\left(L_{i j}\right)
$$

where $\Psi\left(k_{i j}\right)=\phi\left(k_{i j}\right)-k_{i j}\left\{1-\Phi\left(k_{i j}\right)\right\}$

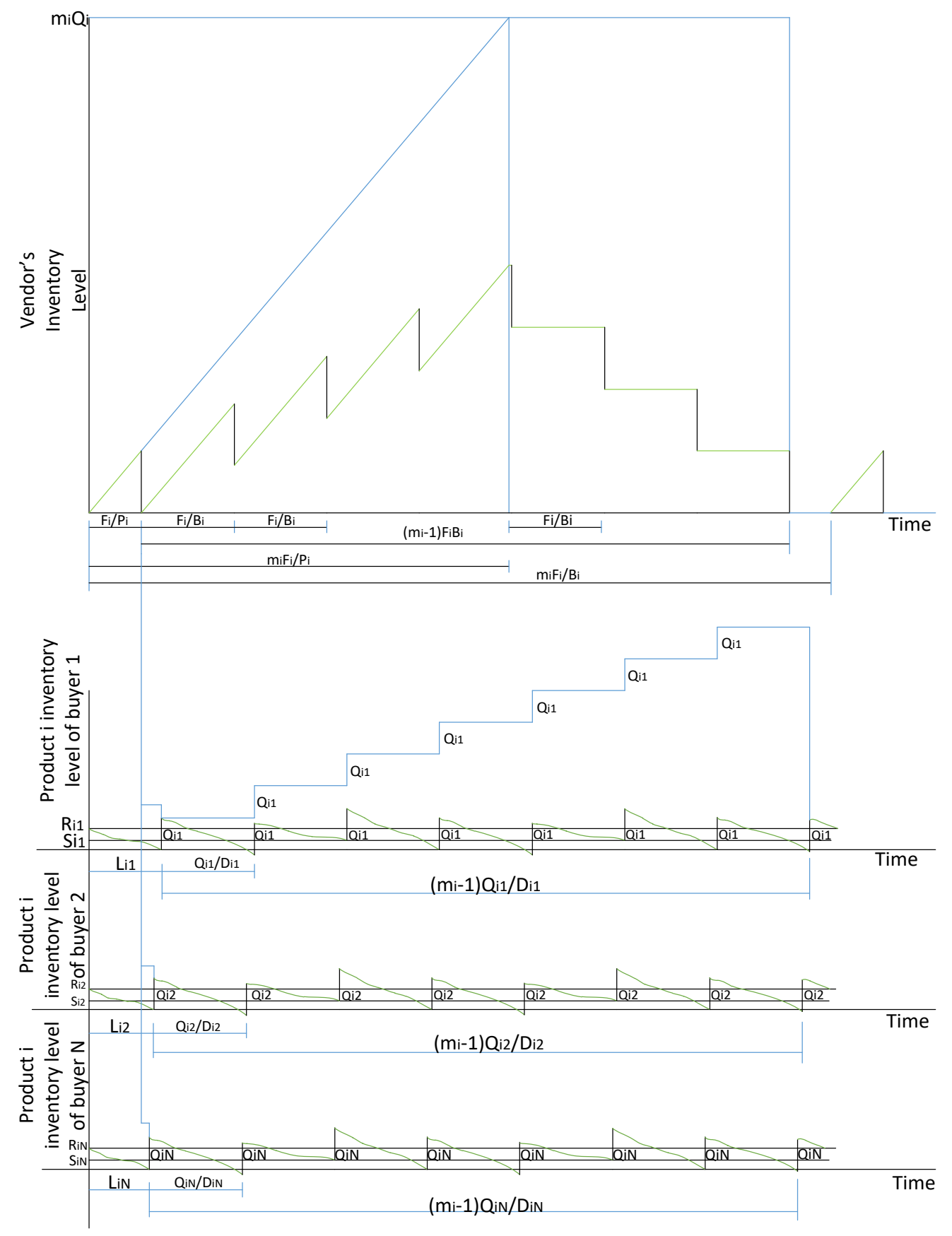

Figure 1 Inventory integration model of one vendor, multi buyers for products i

In this mathematical model, each $L_{i j}$ has an initial value of $L E_{i j}$ and can be reduced to a minimum limit of $L S_{i j}$. The crashing lead time costs $R\left(L_{i j}\right)$ has the value as found in the following;

$\mathrm{R}\left(L_{i j}\right)=\left\{\begin{array}{c}0, \text { if } L_{i j}=L E_{i j} \\ e^{\frac{c_{i j}}{L_{i j}}}, \text { if } L S_{i j} \leq L_{i j}<L E_{i j}\end{array}\right.$ 
The searching procedure for the values of $F_{i}, L_{i j}$, and $m_{i}$ which results in the minimum of the total inventory cost is developed by assuming that the variable $L_{i j}$ is a constant whose value will be changed.

The formula to find the value of $F_{i}$ and $m_{i}$ which results in a minimum total inventory cost is sought by specifying the value of the first partial derivative $T C G\left(F_{i}, L_{i j}, m_{i}\right)$ for each variable and setting them to 0 . Then:

$\frac{\partial T C G\left(\mathrm{~F}_{\mathrm{i}}, \mathrm{L}_{\mathrm{ij}}, \mathrm{m}_{\mathrm{i}}\right)}{\partial \mathrm{F}_{\mathrm{i}}}=0$

It is found that

$$
\begin{gathered}
F_{i}=\sqrt{\frac{2 B_{i}\left[\frac{G_{i}}{m_{i}}+\sum_{j=1}^{N} A_{i j}+\sum_{j=1}^{N}\left[\pi_{i j}+\pi_{0 i j}\left(1-\beta_{i j}\right)\right]\left(\sigma_{i j} \sqrt{L_{i j}} \Psi\left(k_{i j}\right)\right)+\sum_{j=1}^{N} R\left(L_{i j}\right)\right]}{h v_{i}\left[m_{i}\left(1-\frac{B_{i}}{P_{i}}\right)-1+\frac{2 B_{i}}{P_{i}}\right]+\frac{1}{B_{i}} \sum_{j=1}^{N} h_{i j} D_{i j}}} \\
\frac{\partial T C G\left(F_{i}, L_{i j}, m_{i}\right)}{\partial m_{i}}=0 \\
m_{i}=\sqrt{\frac{2 G_{i} B_{i}}{h v_{i} F_{i}^{2}\left[1-\frac{B_{i}}{P_{i}}\right]}}
\end{gathered}
$$

It is also found that

As shown in Equation 4 that the value of $m_{i}$ is also the function of $F_{i}$, then $F_{i}$ can also be expressed by the following;

$$
\mathrm{F}_{\mathrm{i}}=\frac{1}{\mathrm{~m}_{\mathrm{i}}} \sqrt{\frac{2 \mathrm{G}_{\mathrm{i}} \mathrm{B}_{\mathrm{i}}}{\mathrm{hv}_{\mathrm{i}}\left[1-\frac{\mathrm{B}_{\mathrm{i}}}{\mathrm{P}_{\mathrm{i}}}\right]}}
$$

Equations 3 and 5 should have the same value. By completing the two equations, the $m_{i}$ value can be obtained, which will produce the minimum total inventory cost without the decision variable $F_{i}$.

Let $\omega_{i}=2 G_{i} B_{i}$

$\rho_{i}=2 B_{i}\left[\sum_{j=1}^{N} A_{i j}+\sum_{j=1}^{N}\left[\pi_{i j}+\pi_{0 i j}\left(1-\beta_{i j}\right)\right]\left(\sigma_{i j} \sqrt{L_{i j}} \Psi\left(k_{i j}\right)\right)+\sum_{j=1}^{N} R\left(L_{i j}\right)\right]$

$\gamma_{i}=h v_{i}\left[1-\frac{B_{i}}{P_{i}}\right] ; \quad \theta_{i}=-h v_{i}+\frac{2 h v_{i} B_{i}}{P_{i}}+\frac{1}{B_{i}} \sum_{j=1}^{N} h_{i j} D_{i j} \quad ; \quad \tau_{i}=\sqrt{\frac{2 G_{i} B_{i}}{h v_{i}\left[1-\frac{B_{i}}{P_{i}}\right]}}$

Then Equation 3 can be rewritten as; $F_{i}=\sqrt{\frac{\frac{\omega_{i}}{m_{i}}+\rho_{i}}{\gamma_{i} m_{i}+\theta_{i}}}$

Equation 5 can also be rewritten as $F_{i}=\left(1 / m_{i}\right) \tau_{i}$

From those two equations it can be found the value of $m_{i}$ is

$$
m_{i}=\sqrt{\frac{\tau_{i}^{2} \theta_{i}}{\rho_{i}}}
$$

The Hessian matrix has been used to prove that the result has the minimum local point. To find the Hessian matrix value it is necessary to find the second partial derivative value of the TCG $\left(F_{i}, L_{i j}, m_{i}\right)$ for each variable. Based on the calculations, it can be seen that all leading principal minor values for all Hessian matrices have values greater than zero. 


\section{Results and Discussion}

The procedure for finding the values of $F_{i}, L_{i j}$, and $m_{i}$, which results in a minimum total inventory cost, is carried out for each item. The procedure can be seen in the Figure 2.

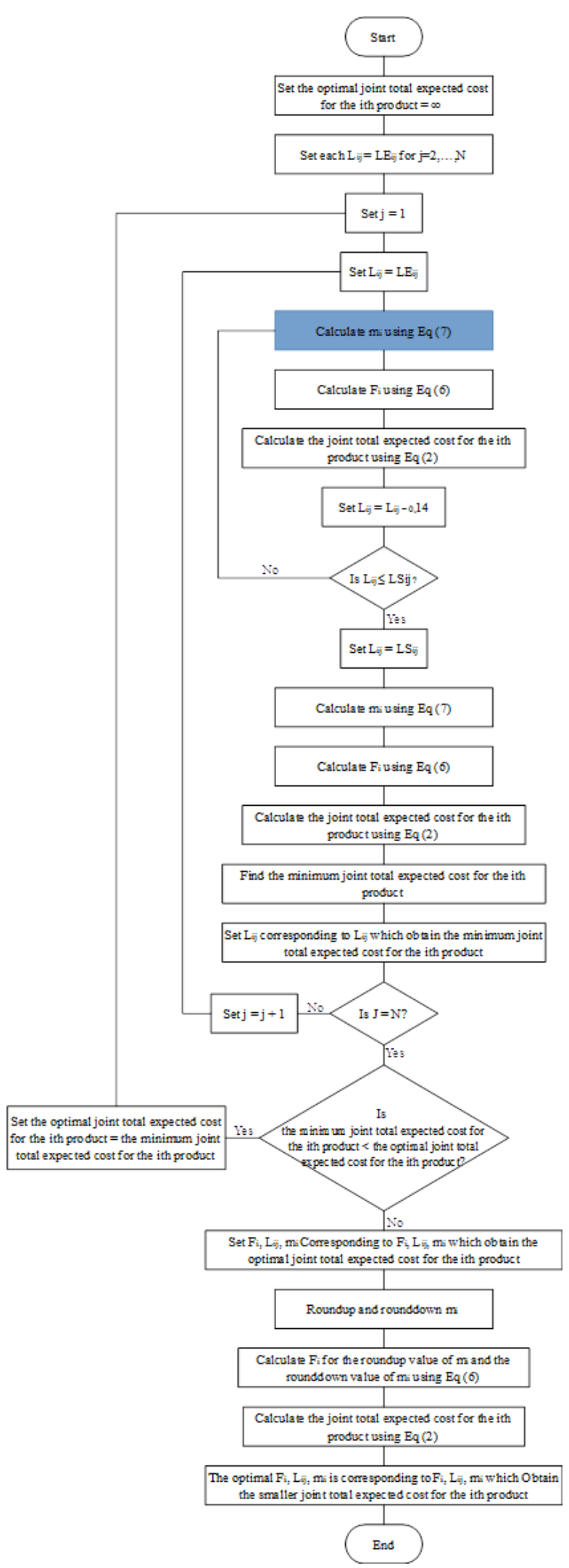

Figure 2 The procedure for finding the optimal value for $F_{i}, L_{i j}$, and $m_{i}$ for product $i$ 
Each case has its own parameters or data and the goal is to determine the values of $F_{i}$, $L_{i j}$, and $m_{i}$. The model was applied for the case of one vendor, two buyers, and two products using data from Table 1 . The purposes are to determine the optimal value for variables $F_{i}$, $L_{i j}$, and $m_{i}$ for item 1 and 2 . The initial value of $L_{11}$ and $L_{12}$ are equal to 3 and 4 , respectively. The values of $L_{11}$ and $L_{12}$ are changed interchangeably and are reduced by 0.14 to reach $L S_{11}$ and $L S_{12}$. For each combination of $L_{11}$ and $L_{12}$, the values of $m_{1}, F_{1}$, and the total inventory cost are calculated using Equations 7, 6 and 3. To get the integer value of $m_{1}$, the value will be rounded up and down and the values of which give in a smaller total inventory cost is the optimal solution. The same procedures are also used for the item 2 . Table 2 is the recapitulation of the optimal solutions which give the minimum total cost of inventory.

Table 1 The case study data

\begin{tabular}{|c|c|c|c|c|c|c|}
\hline$G_{1}$ & $=\$ 600 /$ setup & $A_{12}$ & $=\$ 18 /$ order & \multicolumn{2}{|c|}{$L S_{12}=2$ weeks } & $c_{22}=\$ 5 /$ week/order \\
\hline$G_{2}$ & $=\$ 500 /$ setup & $A_{22}$ & $=\$ 12 /$ order & $L S_{22}$ & $=1$ week & $\begin{array}{l}h_{11}= \\
\$ 20 / \text { unit/year }\end{array}$ \\
\hline$h v_{1}$ & $=\$ 15 /$ unit $/$ year & $\sigma_{11}$ & $=7$ unit/week & $\beta_{11}$ & $=0.5$ & $\begin{array}{l}h_{21}= \\
\$ 15 / \text { unit/year }\end{array}$ \\
\hline$h v_{2}$ & $=\$ 10 /$ unit $/$ year & $\begin{array}{l}\sigma_{21} \\
\text { unit// }\end{array}$ & $\begin{array}{l}=10 \\
\text { veek }\end{array}$ & $\beta_{21}$ & $=0.5$ & $\begin{array}{l}h_{12}= \\
\$ 18 / \text { unit/year }\end{array}$ \\
\hline $\begin{array}{l}P_{1} \\
\text { unit/ }\end{array}$ & $\begin{array}{l}=3.000 \\
\text { jear }\end{array}$ & $\begin{array}{l}\sigma_{12} \\
\text { unit// }\end{array}$ & $\begin{array}{l}=20 \\
\text { veek }\end{array}$ & $\beta_{12}$ & $=0.5$ & $\begin{array}{l}h_{22}= \\
\$ 12 / \text { unit/year }\end{array}$ \\
\hline $\begin{array}{l}P_{2} \\
\text { unit/ }\end{array}$ & $\begin{array}{l}=2.500 \\
\text { year }\end{array}$ & $\begin{array}{l}\sigma_{22} \\
\text { unit/s }\end{array}$ & $\begin{array}{l}=15 \\
\text { veek }\end{array}$ & $\beta_{22}$ & $=0.5$ & $\pi_{11}=\$ 50 /$ unit \\
\hline$D_{11}$ & $=600$ unit $/$ year & $L E_{11}$ & $=3$ weeks & $q_{11}$ & $=0.2$ & $=\$ 45 /$ unit \\
\hline $\begin{array}{l}D_{21} \\
\text { unit/ }\end{array}$ & $\begin{array}{l}=1.000 \\
\text { jear }\end{array}$ & $L E_{21}$ & $=4$ weeks & $q_{21}$ & $=0.2$ & $\pi_{12}=\$ 60 /$ unit \\
\hline $\begin{array}{l}D_{12} \\
\text { unit/ }\end{array}$ & $\begin{array}{l}=2.000 \\
\text { jear }\end{array}$ & $L E_{12}$ & $=4$ weeks & $q_{12}$ & $=0.2$ & $=\$ 55 /$ unit \\
\hline$D_{22}$ & $=800$ unit $/$ year & $L E_{22}$ & $=3$ weeks & $q_{22}$ & $=0.2$ & $=\$ 100 /$ unit \\
\hline$A_{11}$ & $=\$ 20 /$ order & $L S_{11}$ & = 1 week & $c_{11}$ & $=\$ 5 /$ week $/$ order & $=\$ 125 /$ unit \\
\hline$A_{21}$ & $=\$ 15 /$ order & $L S_{21}$ & $=2$ weeks & $c_{21}$ & $=\$ 5 /$ week $/$ order & $\pi_{012}=\$ 120 /$ unit \\
\hline & & & & $c_{12}$ & $=\$ 5 /$ week $/$ order & $\pi_{022}=\$ 110 /$ unit \\
\hline
\end{tabular}

Table 2 Recapitulation of optimal solutions for the case study

\begin{tabular}{cccccccc}
\hline$L_{11}$ & $L_{12}$ & $m_{1}$ & $F_{1}$ & $L_{21}$ & $L_{22}$ & $m_{2}$ & $F_{2}$ \\
\hline 1.6 & 2 & 4 & 312.216 & 2 & 1.46 & 3 & 292.763 \\
\hline
\end{tabular}

\subsection{Sensitivity Analysis}

This section reveals the sensitivity analysis that was performed for the parameter values of $\beta_{i j}, c_{i j}, L E_{i j}, L S_{i j}$, and $\sigma_{i j}$.

a. The Parameter of the Backorder Fraction for item $i\left(\beta_{i j}\right)$. When the $\beta_{i j}$ value decreases, the $F_{i}$ value will tend to increase. Conversely, when the parameter $\beta_{i j}$ increases, the value of $F_{i}$ will also tend to decrease. The parameter $\beta_{i j}$ has an effect on the value of $L_{i j}$. The parameter $\beta_{i j}$ does not have much effect on the value of $m_{i}$. The total inventory cost will decrease by around $3.3 \%$ when the parameter $\beta_{i j}$ increases by $20 \%$ and will increase by around $3.5 \%$ when the parameter $\beta_{i j}$ decreases by $20 \%$.

b. The Positive Constant on Exponential Function Crashing Lead Time Cost of Buyer $j$ and item i $\left(c_{i j}\right)$. When the value of $c_{i j}$ decreases, the $F_{i}$ value will tend to decrease. Conversely, when the parameter $c_{i j}$ increases, the value of $F_{i}$ will also tend to increase. However, the 
increase and decrease are not very significant. The $L_{i j}$ value will increase or decrease when the $c_{i j}$ parameter is changed by $\pm 5 \%$. The total inventory cost will also change by $+2 \%$ and $-1.7 \%$ if the value $c_{i j}$ is changed by $+20 \%$ and $-20 \%$, respectively.

c. The Initial Parameter Value of Lead Time for Buyer $j$ and Item $i\left(L E_{i j}\right)$. This parameter does not have enough effect on the value of $F_{i}, L_{i j}$, and $m_{i}$. When this parameter decreases or increases by 0.7 , the values of $F_{i}, L_{i j}$, and $m_{i}$ do not change.

d. The Lower Limit Parameter Lead Time for Buyer $j$ and Item $i\left(L S_{i j}\right)$. When this parameter $L S_{i j}$ decreases, the value of $F_{i}$ will also tend to decrease. Conversely when the parameter $L S_{i j}$ increases, then the value of $F_{i}$ will also tend to increase. The parameter $L S_{i j}$ is quite influential on the value of $L_{i j}$. The parameter $L S_{i j}$ does not have an effect on the value of $m_{i}$. The total inventory cost will increase by around $3.5 \%$ when this parameter increases 0.7 and will decrease by around $2.4 \%$ when this parameter decreases 0.7 .

e. The Demand Standard Deviation Parameter of Buyer $j$, Item $i\left(\sigma_{i j}\right)$. When the parameter $\sigma_{i j}$ decreases, the value of $F_{i}$ will tend to decrease. Conversely, when this parameter increases, the value of $F_{i}$ will also tend to increase. The parameter $\sigma_{i j}$ is quite influential on the value of $L_{i j}$. The $m_{i}$ value will decrease when $\sigma_{i j}$ increases by $20 \%$. The total inventory cost will increase or decrease if this parameter increases or decreases, respectively.

\section{Conclusions}

The following are the conclusions of the study: (1) The equation of the total inventory cost between a vendor and many buyers and products, the existence of a stock out, and the possibility for buyers to reduce the lead time has been modeled; (2) The total order of all buyers that can minimize the total inventory cost between vendor and buyers has been derived; (3) Lead time that can minimize the total inventory cost between vendor and buyers by considering the possibility for buyers to reduce their lead time was derived; (4) The frequency of shipping in a production cycle that can minimize the total inventory cost between vendors and buyers has also been derived costly, and it does not affect the interior spaces. Also, this method can be applied to existing buildings which reduces the need for mechanical heating or cooling systems and associated costs. Last, considering the quality of materials and their associated infiltration rates, designers can draft intelligent façades to increase the energy efficiency of new and existing buildings by adapting the geometries to account for wind pressure and direction.

\section{Acknowledgements}

The authors would like to thank to Department of Industrial Engineering, Faculty of Industrial Technology - Universitas Katolik Parahyangan, Bandung for all supports.

\section{References}

Ashari, H., Yusoff, Y.M., Zamani, S.N.M., Talib, A.N.A., 2018. A Study of the Effect of Market Orientation on Malaysian Automotive Industry Supply Chain Performance. International Journal of Technology, Volume 9(8), pp. 1651-1657

Ben-Daya, M., Raouf, A., 1994. Inventory Models Involving Lead Time as a Decision Variable. Journal of the Operational Research Society, Volume 45(5), pp. 579-582 
Chang, C.T., Chang, S.C., 2001. On the Inventory Model with Variable Lead Time and PriceQuantity Discount. Journal of the Operational Research Society, Volume 52(10), pp. 1151-1158

Chen, K. K., Chang, C. T., 2007. A Seasonal Demand Inventory Model with Variable Lead Time and Resource Constraints. Applied Mathematical Modelling, Volume 31(11), pp. 2433 2445

Ivan, D.W., Hui, M.W., 2018. An Integrated Vendor Buyer Inventory Model with Transportation Cost and Stochastic Demand. International Journal of Systems Science: Operation \& Logistics, Volume 5(4), pp. 295-309

Jha, J.K., Shanker, K., 2013. Single-Vendor Multi-Buyer Integrated Production-Inventory Model with Controllable Lead Time and Service Level Constraints. Applied Mathematical Modelling, Volume 37, pp. 1753-1767

Jha, J., Shanker, K., 2009. Two-echelon Supply Chain Inventory Model with Controllable Lead Time and Service Level Constraint. Computers \& Industrial Engineering, Volume 57, pp. 1096-1104

Liao, C.J., Shyu, C.H., 1991. An Analytical Determination of Lead Time with Normal Demand. International Journal of Operations \& Production Management, Volume 11(9), pp. 72 78

Miro, E.D., Martin, J.L., Lopez, L., Sescon, J., Oracion, C., Loanzon, J., 2018. A Supply Chain Profile of a School-based Feeding Program using the Centralized Kitchen Model. International Journal of Technology, Volume 9(7), pp. 1394-1404

Mofokeng, T.M., Chinomona, R., 2019. Supply Chain Partnership, Supply Chain Collaboration, and Supply Chain Integration as the Antecedents of Supply Chain Performance. South African Journal of Business Management, Volume 50(1), pp. 1-10

Moon, I., Choi, S., 1998. A Note on Lead Time and Distributional Assumptions in Continuous Review Inventory Models. Computers \& Operations Research, Volume 92(11), pp. 10071012

Ouyang, L.Y., Wu, K.S., 2004. Integrated Vendor-Buyer Cooperative Models with Stochastic Demand in Controllable Lead Time. International Journal Production Economics, Volume 92, pp. 255-266

Ouyang, L.Y., Yeh, N.C., Wu, K.S., 1996. Mixture Inventory Model with Backorders and Lost Sales for Variable Lead Time. Journal of the Operational Research Society, Volume 47(6), pp. 829-832

Pan, J.C., Yang, J.S., 2002. A Study of Integrated Inventory with Controllable Lead Time. International Journal of Production Research, Volume 40(5), pp. 1263-1273

Riazi, S.R.M., Nawi, M.N.M., 2018. Project Delays in the Malaysian Public Sector: Causes, Pathogens and the Supply Chain Management Approach. International Journal of Technology, Volume 9(8), pp. 1668-1680

Tersine, R., 1994. Principles of Inventory and Materials Management. New Jersey: Prentice Hall, Inc.

Vijayashree, M., Uthayakumar, R., 2016. Inventory Models Involving Lead Time Crashing Cost as an Exponential Function. International Journal of Managing Value and Supply Chains, Volume 7(2), pp. 29-39

Yang, J.S., Pan, J.C., 2004. Just-in-time Purchasing: An Integrated Inventory Model Involving Deterministic Variable Lead Time and Quality Improvement Investment. International Journal of Production Research, Volume 42(5), pp. 853-863

Zhu, X.X., Xu, X., 2012. An Integrated Optimization Model of a Closed Loop Supply Chain under Uncertainty. Journal of System and Management Science, Volume 2(3), pp. 9-17 